\title{
Gabriela de Hispanoamérica
}

Gabriela representa no sólo una fecha en la literatura chilena, sino también un signo de la literatura hispanoamericana. Indudablemente la poesía chilena ocupa uno de los más altos puestos en el idioma. (LUIs A. SÁNCHEZ, Nueva Historia de la Literatura Americana [Buenos Aires, 1943]).

\footnotetext{
$\mathrm{F}^{\mathrm{N}}$ las historias de la literatura hispanoamericana solía $D$ considerarse a Chile como tierra de sólo historiadores y juristas. Parecía dogma irrefutable la afirmación del sabio don Marcelino Menéndez y Pelayo, que escribía, en 1895: "De la Universidad ${ }^{1}$ salieron historiógrafos, investigadores, gramáticos, economistas y sociólogos, más bien que poetas. El carácter del pueblo chileno es positivo, práctico, sesudo, poco inclinado a idealidades. Esta limitación está bien compensada por excelencias más raras y más útiles en la vida de las naciones... No pretendemos por eso que haya de durar siempre. Dios hace nacer el genio poético donde quiere y no hay nación ni raza que esté deseheredada de este don divino."2

Pues, ese milagro divino con que nos consolaba el mal profeta de don Marcelino, se ha cumplido con creces. No sé por

a La Universidad de Chile, fundada en 1853, sobre la tradición de la Real Universidad de San Felipe (siglo xviI), en Santiago. Su primer Rector, don Andrés Bello.

2 Marcelino Menéndez y Pelayo, Antología de la poesía bispanoamericana, "Introducción".
} 
qué pensaba que los poetas debieran salir de las universidades... Pero, como señala Fernando Alegría, ${ }^{3}$ la alta poesía actual de Chile no ha brotado por generación espontánea. Por lo demás el propio Menéndez y Pelayo cita a Andrés Bello que dice: "Chile es el único de los pueblos modernos cuya fundación ha sido inmortalizada por un poema épico".4 Y don Alonso de Ercilla y Zúñiga era también mestizo de vasco, como nuestra Gabriela. Doña Mercedes Marín del Solar, celebrada por el gran polígrafo español, anunciaba con medio siglo de anticipación las elegantes audacias del Modernismo; y Darío publicó en Chile (Valparaíso, 1888), su $A z u l$, partida de nacimiento del Modernismo.

Tres poetas chilenos, Gabriela Mistral, Vicente Huidobro y Pablo Neruda, han tenido significación máxima en la evolución de la lírica hispánica desde Rubén. Gabriela y Pablo han inmortalizado seudónimos. Lucila Godoy Alcayaga adoptó un suave nombre de Arcángel y un apellido que recuerda al dulce cantor provenzal, a quien nombraba entre sus predilectos. No puedo llamarla "poetisa", que suena a poeta a medias; $y$ Gabriela es todo un poeta.

\section{Poesia de Iberoamérica.}

A mi juicio, Gabriela Mistral representa mejor que nadie el alma poética de Hispanoamérica. Esta mujer dolorida y suave, solitaria y vagabunda, tierna y fuerte, llevaba dentro de la entraña desgarrada y virginalmente fecunda cada rincón de América y tenía canción para todas las niñeces y todas las maternidades; y lino para cada llaga del indio y del humilde, entre nuestras sierras y nuestros mares.

Nació Lucila Godoy Alcayaga el 7 de abril de 1889 en el villorrio de Montegrande, cerca de Vicuña, en el Valle de Elqui, en medio de la sal de los nitratos y el rojo cobre de las soledades nortinas. En el desierto de su vida, el oásis del valle de Elqui se le quedó para siempre cobijado en el recuerdo: "mis niñeces del valle de Elqui...", "mis cerros de Elqui...", "húmeda axila en el cuerpo del desierto chileno..."

3 Fernando Alegría, Poesia cbilena (México, 1954).

* Menéndez y Pelayo, op. cit., loc. cit. 
Durante una larga ausencia de la patria sigue identificándose hasta tal punto con su campo natal de Chile, que siente que la fuerza varonilmente sobrehumana de su verso tiene raíces en "la chilenidad en su aspecto terco y fuerte". $\mathrm{Y}$ así, la montañesa chilena, mestiza de vasco, escribe: "He cantado cosiendo mis cerros/ por cogerte en el grito los pies."'

Un artista no es humano y universal si no siente hondamente lo propio. El más universal de los escritores de nuestra lengua, Cervantes, es el más español de todos. En Gabriela, americana por chilena, el amor a la patria, su real esencia americana, está siempre vivo y ardiente. La "Chilena errante", como gustaba llamarse, no nos da un patrioterismo oratorio ni el mal gusto de una politiquería ramplona. Es la conciencia de su misión de artista de decir lo suyo.

Dicha conciencia maduró en América con el Modernismo. Hija y profetiza de los Andes, canta Gabriela a su cordillera nevada y enhiesta:

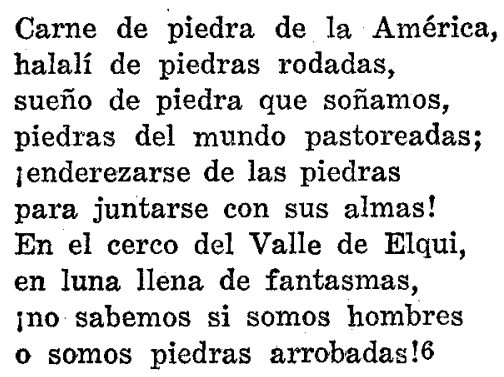

Donde la comunión del hombre y el paisaje se dignifica mágicamente. $Y$ luego increpa a la columna vertebral de la América del Sur, para que la médula común una a los pueblos iberoamericanos:

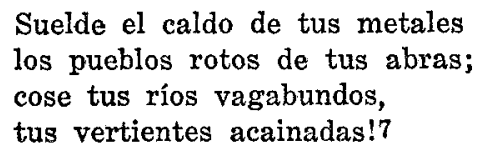

5 Gabricla Mistral, T'ala, "Cordillera".

6 Ibid.

7 Ibid. 
Al proponerse entonar - - sin las rumbosas pretensiones de Chocano, que se creyó dueño del Sur como Whitman tenía el Norte_- el himno grande de América llama a su intento "balbuceo": "Yo sé muy bien que doy un puro balbuceo del arduo asunto. Igual que otras veces, afronto el ridículo con la sonrisa buena de la mujer rural cuando se le malogra el frutillar o el arrope en el fuego..."

Lamenta que no hiciera Darío el Himno de América, "por no haberse perdido en la naturaleza americana". Que de haberlo hecho el maestro, ya esos himnos "andarían entonando el alma del mocerío". Una mujer rural, balbuceante, ha cantado, con mayor pureza que Neruda y casi con idéntico frenesi de imágenes encabalgadas, el himno de la América nuestra.

En esos himnos de la tierra americana ("Cordillera", "E.] maíz", "Salto del Laja", "Sol de Trópico", etc.), su verso es a veces intencionado $\mathrm{y}$, a la vez espontáneamente, duro, asimétrico, con raro dominio del eneasílabo y con la directa sinceridad de las piedras andinas : austeras, repetidas, variadas y limpias.

\section{El tema indio.}

El tema indio no reviste en Gabriela el tono airado o hiriente de los enconados "poetas-demagogos" (si es que este contrasentido existe). Es un amor a lo propio y una de las expresiones de su cristiano amor por los humildes. Como muestra del primer aspecto de su "indigenismo", valga su versión poética del "Salto del Laja", catarata que se descabella majestuosamente en pleno corazón de Araucanía:

\footnotetext{
Salto del Laja, viejo tumulto, hervor de las flechas indias, despeño de belfos vivos, majador de tus orillas...9
}

$Y$ mientras revive la visión histórica de la raza mapuche -ante el escenario de la salvaje cabellera desatada en medio

8 Tala, "Nota a Cordillera".

9 Tala, "Salto del Laja". 
de bosques de araucarias y canelos-, se identifica con la vida del agua y con la tierra a que se entrega:

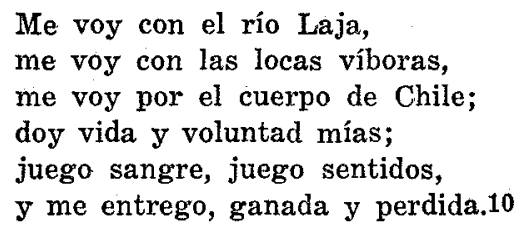

En "La Cuenta-Mundo" explica a los niños el sentido del aire, de la luz, del agua, del pinar, el fuego, la casa y la tierra. Pero es la tierra americana virgen. Y maternalmente dice:

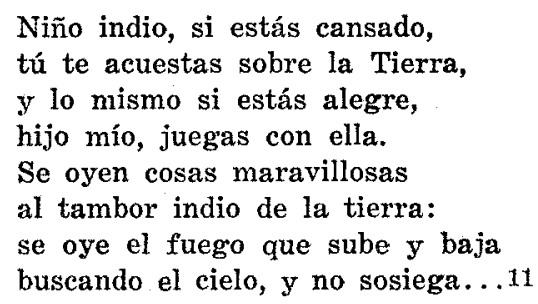

$Y$ es el tan-tan de las canciones araucanas, que van cayendo monorrítmicas —desteñido son guerrero- en el alma de la triste tierra volcánica.

Idéntica comunión con la tierra hay cuando canta la milpa ${ }^{12}$ y el indito mejicano; o al negro de Cuba o a la isla de palmas de Puerto Rico, "apenas posadura sobre las aguas..."

\section{Amor-Dolor-Ternura.}

Pero más que paisaje y tierra -fondo de sus cuadros poéticos-, los temas profundos de Gabriela, punzantes de tremenda originalidad, son los temas humanos; universales, pero particularmente vividos, del amor, del dolor, de la muerte. Verso agrio, ensangrentado y fuerte. $\mathrm{Y}$ el tema de la maternidad. Primero, una maternidad de ilusión y desencanto.

10 Ibid.

11 Ibid., "Cuenta-Mundo".

12 En México, campo de maíz, 
Luego, la flor del yermo se reviste de majestuosa serenidad en las cenizas de la cabeza egregia. La dulce maternidad para los niños todos: los ajenos, los pobres, los abandonados, los soñados. Es la maestra que canta; la madre que mece. Es la suprema canción sin trueque de ternuras, como una sacerdotisa de la suavidad maternal de la mujer - tan india y tan hispana a la vez-, escondida apenas la voz del cilicio.

El amor único de Lucila Godoy trajo ya en sus alucinaciones veinteañeras un torcedor. "La tierra se hace madrastra —si tu alma vende a mi alma..."' Sus primeros gritos de dolor trágico no tienen parangón en la lengua española y acaso sólo raíces en el Libro de Job o los terribles profetas del Testamento Viejo.

Luego vino el leve quejido de la balada aquella: “Él pasó con otra;/ yo le ví pasar..."

$Y$ desde entonces la sensitiva sabe el "difícil oficio" de amar; y siente que todo en su boca adquiere: "un sabor persistente de lágrimas:/ el manjar cotidiano, la trova/ y hasta la plegaria!"'13

Su alma cristiana, en agria plegaria perfumada de mirra, es un eco del "Eloi, Eloi, lamma Sabachtani!" del Redentor:
Padre nuestro, que estás en los cielos, por qué te has olvidado de mí!14
Me vendió el que besó mi mejilla, me vendió por la túnica ruin.
Yo en mis versos el rostro con sangre, como Tú sobre el paño, le dí...15

Mientras Lucila Godoy trabaja, a los veinte años, de maestra en una de tantas aldeas en que sirvió, recibe la noticia del suicidio amado. En el bolsillo del joven Ureta han encontrado una tarjeta con su nombre: Lucila Godoy. Y rompe el costado herido de Gabriela el ronco grito, huraño y tierno, feroz, de sus "Interrogaciones" y sus "Sonetos de la Muerte" (que no sabemos si fueron originalmente tres o doce), escritos en 1909.

\footnotetext{
13 Gabriela Mistral, Desolación, "Balada".

14 Ibid., "Padre nuestro".

15 Ibid.
} 
En los Juegos Florales de Sạtiago, en 1914, con la Flor Natural ganada por los Sonetos, hace su entrada en el parnaso americano la dulce y extraña maestra rural.

La que era capaz de cantar ante la muerte del amado infiel:

...Me alejaré cantando mis venganzas hermosas, iporque a ese hondor recóndito la mano de ninguna bajará a disputarme tu puñado de huesos!16

Luego en sus "Interrogaciones" se encara con el Señor, como Abraham regateando el perdón de las ciudades nefandas:

¿Cómo quedan, Señor, durmiendo los suicidas?

¿ Un cuajo entre la boca, las dos sienes vaciadas, las lunas de los ojos albas y engrandecidas, hacia un ancla invisible las manos levantadas ?...

$Y$ responde, Señor, cuando se fuga el alma por la mojada puerta de las largas heridas, ¿ entra en la zona tuya hendiendo el aire en calma, o se oye el crepitar de alas enloquecidas?

Tal el hombre asegura, por error o malicia, mas yo, que te he gustado como un vino, Señor, mientras los otros siguen llamándote Justicia, ¡no Te llamaré nunca otra cosa que Amor!...17

La boca le quedó alicaída como ave rota. El tema maternal florece de frustrado dolor. Para elevarse, a través del fuego $y$ de la sangre, hasta una serena y clara maternidad universal.

\section{Primero:}

Un hijo, un hijo, un hijo! Yo quise un hijo tuyo y mío, allá en los días del éxtasis ardiente...18

\section{Luego :}

Apacenté los hijos ajenos, colmé el troje con los trigos divinos y sólo a Ti espero.

16 Ibid., "Sonetos de la muerte, I".

17 Ihid., "Interrogaciones".

18 Ibid, "Poema del hijo". 
¡Padre nuestro que estás en los cielos, recoge mi cabeza mendiga, si en esta noche muero!19

IV. La evolución de las formas.

En las formas poéticas de la obra de Gabriela Mistral hay una evolución que vale la pena señalar. ${ }^{20}$

En Desolación hay dieciséis poemas alejandrinos modernistas; en Tala, sólo cuatro y en Lagar, uno. El endecasílabo es usado en 19 poemas de Desolación, en 13 de Tala y 14 de Lagar. El eneasílabo, que sólo ensaya en seis poemas de $D e-$ solación, campea en 22 de Lagar. El octosílabo tradicional, del romance y la copla, que Gabriela prefiere para las canciones íntimas, domina en 29 poemas de Desolación, está en sólo 12 de Tala y vuelve a imperar en 36 poemas de Lagar.

El uso preferente de los versos de arte menor es un síntoma común de la lírica postmodernista y actual. Sea un decidido deseo de sencillez, como en Machado o Juan Ramón Jiménez; sea por la influencia de los romances de García Lorca, en que lo popular y la imaginería se conjugan; sea porque se acomodan mejor a la expresión de las cosas mínimas. Las Odas elementales de Neruda y Lagar de Gabriela cantan las "cosas" y lo hacen en el verso casero, tradicional de la poesía popular castellana. En heptasílabos escribió también Juan Ramón la progresiva desnudez de su poesía pura.21

V. Lenguaje y estilo.

Está todavía por hacer el estudio del lenguaje de Gabriela Mistral. Sólo quiero apuntar algunas notas, al concluir mi

19 Ibid.

20 Obras de Gabriela Mistral: Desolación (New York, 1922); Temura (parte de Desolación) (Madrid, 1924); Lecturas de mujeres (prosa) (Madrid, 1924); Vida de San Francisco (sin fecha); Tala (Buenos Aires, 1938); Antologia (Santiago, 1940); Lagar (Santiago) ,1949); Poemas de las madres (1950). Póstumos ha dejado dos libros de poemas: una continuación de Lagar y un largo poema, que contiene lo más hermoso de su poesía desde Desolación, "Recado de Chile". Los eścritores chilenos José Santos González Vera y Hernán Díaz Arrieta (Alone) están a cargo de su publicación. Díaz Arrieta ha venido recientemente a Nueva York para recopilar obra dispersa, y cartas, suyas. El profesor Federico de Onís tiene recopilada su obra dispersa en prosa.

21 Juan Ramón Jiménez, Poesía, Antologia, pág. 411. 
breve estudio. El profesor Entwistle, de Oxford, comparó a Gabriela con Santa Teresa de Jesús.

"Mujer inquieta y andariega", la Santa como Gabriela; fundadora ésta de una nueva Orden de poetisas americanas, tienen ambas un "estilo de hermitaño". En medio de la clásica sencillez del siglo XVI español, la Doctora de Ávila extremaba al colmo la naturalidad. Enseñaba a sus hermanas que debían "mirar a la manera de hablar que vaya con simplicidad y llaneza y relisión... ; que lleve más estilo de hermitaño y gente retirada que no ir tomando vocablos de novedades $\mathrm{y}$ melindres, creo los llaman, que se usan en el mundo."22

$Y$ Mario Osses, un buen crítico chileno, ha podido escribir de Gabriela: "No hay en su poesía el sello eminente de otra alguna [porque en ella] el canto toma forma de mujer, que no de 'literata'."23

Una naturalidad vital, grito elemental de entraña herida, humana y sobrehumana a la vez. En su "Nota al Nocturno de la Derrota", comenta Gabriela: "No sólo en la escritura sino también en mi habla, dejo por complacencia, mucha expresión arcaica, sin poner más condición al arcaísmo que la que sea fácil y llano... El campo americano - y en el campo me crié-, sigue hablando su lengua nueva veteada de arcaísmos abundantes. La ciudad, lectora de libros doctos, cree que un tal repertorio arranca en mí de los clásicos añejos, y la muy urbana se equivoca." 24

"Albricia mía: -dice a propósito de otro poema- en el juego de las Albricias que yo jugaba en mis niñeces del valle de Elqui, sea porque los chilenos nos evaporamos la s final, sea porque las albricias eran siempre cosa en singular -un objeto escondido que se buscaba-, la palabra se volvía una especie de sustantivo colectivo... Puedo corregir en mi seso lo aprendido en las edades feas --adolescencia, juventud, ma-

22 Santa Teresa de Jessús, Modo de visitar los conventos, en Biblioteca de Autores Españoles, LII, pág. 297, b.

23 Mario Osses, "El casticismo de Gabriela Mistral", Atenea (Concepción, Chile), abril de 1949.

24 Gabriela Mistral, Tala, "Nota al Noctumo de la Derorta", 
durez-; pero no puedo mudar de raíz las expresiones recibidas en la infancia".25

Creo que se me perdonará la extensa cita, porque en ella puede estimarse la viveza teresiana, la raíz castiza y la propiedad expresiva de la prosa de Gabriela.

Gabriela no nace de una escuela literaria. Aunque ha tomado elementos del modernismo deslumbrador, del postmodernismo sincero y de la vanguardia audaz. Pero su verso brota, no del "manantial sereno" de Machado, sino de una entraña rota y de unas manos tiernas que han bajado al amado "del ni.cho helado en que los hombres te pusieron a la tierra humilde y soleada..." Pero manos también capaces de hundir en el pecho, y bajo el polvo, el amor trágico: "por que a ese hondor recóndito la mano de ninguna/ bajará a disputarme tu puñadò de huesos...."”

La mujer que "amó mucho" 26 ha descendido a ese polvo de tierra soleada que canta en su libro postrero. De la flor nacida de su sueño angustiado seguirán soñando las generaciones poéticas de habla española. No creo que el verbo del amor humano haya encontrado nunca, para encarnarse, una palabra llameante y una poesía tan alma ni un alma tan poesía, como el canto inmortal de Gabriela de Hispanoamérica: "Su lengua, sus ojos, sus manos.../ polvo serán, mas polvo enamorado!'27

\section{Carlos D. HaMilton, Vassar College, N. Y.}

25 Ibid., "Nota a Albricia".

20 Evangelio de San Lucas, VII, 47.

27 Francisco de Quevedo,Soneto "Cerrar podrá mis ojos..." 